\title{
Does Gender Significantly Predict Academic, Athletic, or Career Motivation Among NCAA Division I College Athletes
}

\author{
Margaret L. Tudor \\ University of Tampa \\ B. David Ridpath \\ Ohio University
}

Abstract: American society has placed college athletics at its core for over a century (Rader, 2009) and it has become ubiquitous in university life. Meaningful engagement outside traditional classroom settings has been found to have positive effects on a student's personal development, regardless of athletic status (Pascarella \& Terenzini, 2005). College athletes' individual experiences have received considerable attention in popular media and literature, as the pressures to perform athletically and academically are vast (Benford, 2007; Meyer, 2005). Previous studies have explored athletic environments via the emergence of leadership, team dynamics, team cohesion, and the motivational climate (Adie, Duda, \& Ntoumanis, 2008; Allen \& Howe, 1998; Balaguer, Duda, \& Crespo, 1999; Medic, Mack, Wilson, \& Starkes, 2007; Tsang, 2007). Other studies have focused more on individual attributes such as motivation to perform and participate, perceived ability, perceived competence, personal satisfaction, enjoyment, and social status (Amorose \& Horn, 2001; Hollembeak \& Amorose, 2005; Reinboth \& Duda, 2004; Sheldon \& Eccles, 2005; Van-Yperen \& Duda, 1999). The purpose of this study was to examine the effects of gender on motivation towards academics, athletics, and career. Data were gleaned from male and female athletes at one large Midwestern NCAA Division I university using the Perceived Motivational Climate in Sport Questionnaire-2 (PMCSQ-2) and the Student Athlete's Motivation toward Sports and Academics Questionnaire (SAMSAQ). Using Harter's (1978) theory of perceived competence and Nicholls' (1984) perceived theory of motivational climate, data are discussed and analyzed using multiple regressions to investigate if gender significantly predicts academic/athletic/career motivation among student-athletes.

Keywords: motivation, gender studies, and career motivation

Scandals in college athletics have surged in the last decade. A commonality among most sport reformers in intercollegiate athletics suggest that "the university's increasing involvement in the entertainment industry, or as many in the movement sardonically refer to as 'edutainment,' is yet another way college sports undermine academe's lofty values" (Benford, 2007, p. 15). Academic scandals have been discovered at several big-time universities (e.g., Minnesota, Tennessee, Louisiana State University, Texas Tech, Georgia, Ohio State, Alabama, Auburn, North Carolina, etc.) that included "cheating by athletes with the assistance of tutors, academic support services, and faculty" (Benford, 2007, p. 17). This has led the National Collegiate Athletic 
Association (NCAA), the primary governing body in intercollegiate athletics, to continually reaffirm its commitments to support and augment the athletic and academic experiences of all college athletes and endure countless reforms, mostly in the last decade (Splitt, 2002).

Some of the aforementioned reforms include the Academic Progress Rate (APR), increased satisfactory progress, and percentage-toward-degree requirements (Meyer, 2005). Academic performance of college athletes in the last ten years has been under a microscope in both the media and the popular literature (Amorose, 2003; Benford, 2007; Meyer, 2005; Pappano, 2012; Ridpath, 2002; 2007). Even with the controversy and challenges, the NCAA touts recent athlete graduation rates of $60 \%$, which is higher than the national average for the nonathletic population at $58 \%$ (NCAA, 2002). The most recent release of Division I men's basketball and Bowl Subdivision football graduation rates indicated a new record high graduation rate that reached or exceeded $70 \%$ (NCAA, 2012). Differences in college athletes' academic performance warrant additional investigation beyond traditional variables such as graduation rates. Such investigation deserves an inclusion of factors that might predict athletes' academic, athletic, and/or career motivation.

The areas of perceived motivational climate, motivation towards academics, and motivation towards athletics are attributes that have shown promising results in the sport domain (Allen \& Howe, 1998; Amorose \& Horn, 2001; Hollembeak \& Amorose, 2005; Medic, Mack, Wilson, \& Starkes, 2007; Reinboth \& Duda, 2004; Sheldon \& Eccles, 2005; Tsang, 2007; VanYperen, \& Duda, 1999). This study sought to examine whether gender significantly predicts student-athletes' motivation towards academics, athletics, and career. With gender being a popular topic in the NCAA as well as in motivation and the motivational climate, this study not only adds to the conversation, but also sheds light on how to facilitate the conversation among leaders, administrators, and support staff in athletic departments across the nation.

\section{Theoretical Framework}

\section{Perceived Competence Motivation}

According to Harter (1978), individuals are innately motivated to be competent in all areas of human achievement. Individuals historically participate in sport for intrinsic reasons, such as enjoyment in the activity, and the pleasure and sense of mastery that comes from learning skills, improving skills, and the thrill of competition. To satisfy the urge to be competent in sport and/or academics, the athlete attempts to master the sport and/or academics. Perceptions of competence then lead to subsequent motivation. As competence motivation increases, the athlete is encouraged

to make further mastery attempts. Thus, perceived competence can be defined as how the individual views his/her ability to master the skill successfully.

\section{Perceived Motivational Climate}

Nicholls (1984) presents a paradigm of achievement motivation in education. He defines achievement motivation as a way for an individual to develop or demonstrate high ability in two ways: reference to one's own performance or mastery, or reference of oneself relative to others. Individuals perceive success as localized within the task itself or within their own ability. In other 
words, the task-involved person will define success through the mastery of skills and will therefore gain a sense of competence upon the successful accomplishment of the task. This individual therefore shows characteristics of task-orientation. The ego-involved person will define success when s/he demonstrates superior performance to others and will gain a sense of competence when this is achieved; the athlete shows characteristics of an ego-orientation. Additionally, Ames (1992) suggests that the educational and sport domains are very similar and promote a development of motivational behaviors in similar ways. For example, if an athlete is task-oriented in athletics, similar strategies consistent with this motivational orientation should be evident in academic motivation as well.

While there are many aspects of life an individual goes through, the motivational climate can affect how the individual is satisfied in the sport domain (Nicholls, 1989). Furthermore, when the coach puts an emphasis on task-involvement (e.g., improvement and mastery) or egoinvolvement (e.g., winning and performance), the athlete would also need to value this to feel satisfied. Nicholls (1989) also found that although peers and parents may contribute to the motivational climate, the coach is often the major influence of the motivational climate and for determining successful performance. When the environment is task-involved, the focus is on the athlete's improvement and successful performance is determined through mastery of the skill. When the environment is ego-involved, the focus is on winning. Here, athletes may try to avoid punishments and may cheat due to the emphasis on winning. The perceived motivational climate is a crucial determinant of perceived success of the individual. Motivational climate often reflects a coach's philosophy on success. If there is a contradiction in standards of living between the coach and the athlete, the athlete might show lower levels of motivation in one or more of the environments.

\section{Motivation}

The concept of intrinsic and extrinsic motivation is frequently associated with success in the educational setting. Deci and Ryan (1985) and Ryan and Deci (2000a) define intrinsic motivation as doing an activity for its own sake, whereas extrinsic motivation refers to doing an activity to achieve an instrumental goal, such as a championship trophy. Furthermore, the authors postulate that all intrinsically and extrinsically motivated individuals have an innate sense towards personal growth. Although Nicholls' (1984) concept of achievement motivation and the concept of intrinsic and extrinsic motivation (Deci \& Ryan, 1985; Ryan \& Deci, 2000a) are theoretically related, the two variables are conceptually distinct. Further research is needed to clarify this issue in the sport setting.

Expectancy-value frameworks have often been used in motivational research in the collegiate athletic setting. Here, motivation definitions include the intensity and direction of behavior (Silva \& Weinberg, 1984). Intensity can be referred to as the amount of effort an individual applies to a certain task and direction can be referred to as the choice to pursue such task. Thus, the individual's choice of and effort placed toward a task would signify his/her motivation. College athletes have made a choice to participate in both athletics and academics; however, the amount of effort they put forth towards each might vary significantly. In expectancyvalue theory, an individual's self-concept about their ability to complete a task successfully, along with the level of difficulty associated with such task, influences the probability or expectancy of 
success (Eccles, 1983; Vroom, 1964). Additionally, an individual will place a value on a specific task, which is a utility of the extent to which the task satisfies a need, aids in current goal attainment, and fulfills a future goal.

The instrument used in this study was constructed from an expectancy-value motivation framework (Shuman, 2009). Achievement motivation theories have a basic assumption that motivation toward a specific task is determined by an individual's choice of, persistence on, and amount of effort applied to a task (Weiner, 1984). Theoretically speaking, individuals who are highly motivated to approach achievement would give a great deal of energy and time toward successful completion of a specific task. As Eccles (1983) postulates, expectancy is influenced by the individual's perception about their capability to successfully complete a task and the level of difficulty associated with completing the task. Thus, the value attached to a task is a function of the extent to which the task fulfills a need, aids in current goal attainments, and fulfills a future goal.

\section{Summary of Theoretical Framework}

Using the aforementioned models, college athletes' motivation focuses on the reward, such as obtaining a college degree, much like the extrinsic motivation that Harter's (1978) model explains. However, as Gaston-Gayles (2004) noted, "research on the academic performance of college athletes should focus on factors related to academic success" (p. 75). Unlike the popular opinion that athletes in highly visible (men's) sports, such as football and men's basketball, use college as a stepping-stone to play professionally and have little intention of pursuing a degree, Adler and Adler (1987) found that the majority of basketball players in their study had been optimistic about obtaining a degree when they first entered college. Unfortunately, the players' athletics, social, and classroom experiences created an anti-intellectual atmosphere that, over time, inhibited academic success. It was found that athletes adjusted their academic plans throughout their college years by lowering their educational goals (Adler \& Adler, 1987).

Furthermore, some college athletes might be intrinsically motivated towards academics due to a belief in their capacity to accomplish the task (similar to task-orientation), and others will be extrinsically motivated due to an awareness of the value of completing a college degree (similar to ego-orientation). Therefore, a task-involved climate (as emphasized by the coach with an importance on academics and overall skill development) that underscores individualized improvement may be more beneficial to the athlete by maintaining or enhancing intrinsic motivation towards academics or athletics.

\section{Purpose and Significance of Study}

The purpose of this study was to examine the effects of gender (i.e., men's vs. women's sports) on motivation towards academics and/or athletics as reported by college athletes at a small Division I university. Furthermore, this study sought to examine whether gender, sport visibility, and/or perceived motivational climate significantly predicts athletes' motivation towards academics and/or athletics. That is, the meaning and motivations of being a female or male athlete in intercollegiate athletics was examined through how much emphasis is placed on academics and athletics. 
This study provides an important practical contribution to the leadership and participants of collegiate athletics. This research project seeks to help leaders, including coaches, athletic departments, student-athlete services personnel, and athletes alike to become aware of personal and situational factors that are influenced by the athlete's sport visibility and role on his/her team. These factors are related to the athlete's personal motivation towards athletics and/or academics. This study is also a significant contribution to the existing research literature, answering GastonGayles' (2005) call for studies that examine motivation towards athletics and academics among student-athletes. Findings from this study may assist advisors to aid student-athletes in developing a healthy balance between academics and athletics. Discussions about the flagrant scandals in intercollegiate athletics, along with the disproportionate graduation rates between sports, have also called for further research (Benford, 2007; Meyer, 2005). Thus, this study attempted to inform athletic departments, student-athlete services, coaches, and athletes about the differences in motivation towards athletics and academics.

\section{Research Question}

This study sought to address the following research question and hypotheses:

Does gender significantly predict academic/athletic/career motivation among studentathletes, controlling for other variables in the model?

The following were the hypotheses regarding the primary question that guided this study:

Null: Gender does not significantly predict academic/athletic/career motivation among student-athletes, controlling for other variables in the model.

Alternate: Gender significantly predicts academic/athletic/career motivation among student-athletes, controlling for other variables in the model.

\section{Methods}

Approximately 310 Division I student-athletes at a large Midwestern university were contacted to participate in the study. Of this accessible population, there are seven men's sports (baseball, basketball, cross country, football, golf, hockey, and soccer) and nine women's sports (basketball, golf, gymnastics, soccer, softball, swimming, tennis, track and field, and volleyball). Players were recruited in their respective teams, which assisted in attaining an adequate sample size. Gender is considered the variable between men's and women's sports, which allowed for the researchers to examine the consequences of such differences. Furthermore, highly visible sports are historically considered those sports that either create revenue (also known as revenue producing sports), such as basketball and football (Benford, 2007; Carter, 2012; Meyer, 2005; Shuman, 2009) or are most visible among spectators (The Harris Poll, 2013). Therefore, in this study, men's and women's basketball and football were grouped into the highly visible sport category, while all other sports were grouped into the non-highly visible sport category. Demographic information was collected to gain specific knowledge of age, sex, race, scholarship status, and player role. Student-athletes in this study were recruited from one Midwest Mid- 
American Conference (MAC) University. Table 1 summarizes the frequencies and percentages of these characteristics, with the final sample size being 309 student-athletes $(N=309)$. More specifically, the total number of responses was 310, for a response rate of $100 \%$; however, one response was dropped because it was identified as an outlier. Thus, the sample size was decreased to $309(N=309)$. Although all athletic teams were represented in the sample, approximately fifty student-athletes from the original total number of student-athletes on the rosters of the various teams were not present in the team meetings, yielding a response rate of $86 \%$. Upon closer examination of the student-athletes who were not present, reasons for absence included: having a schedule conflict with classes or training room meetings, graduation, quitting the team, or being late to the meeting.

\section{Table 1}

Frequencies and Percentages of the Demographic Variables

\begin{tabular}{|c|c|c|c|}
\hline \multicolumn{2}{|c|}{ Variables } & \multirow[t]{2}{*}{ Frequency } & \multirow[t]{2}{*}{ Percentage } \\
\hline Sport & & & \\
\hline & Baseball & 29 & 9.4 \\
\hline & Men's Basketball & 13 & 4.2 \\
\hline & Men's Cross Country & 5 & 1.6 \\
\hline & Football & 79 & 25.6 \\
\hline & Men's Golf & 9 & 2.9 \\
\hline & Hockey & 26 & 8.4 \\
\hline & Men's Soccer & 17 & 5.5 \\
\hline & Women's Basketball & 12 & 3.9 \\
\hline & Track and Field & 37 & 12.0 \\
\hline & Women's Golf & 8 & 2.6 \\
\hline & Gymnastics & 15 & 4.9 \\
\hline & Women's Soccer & 12 & 3.9 \\
\hline & Softball & 12 & 3.9 \\
\hline & Swimming & 19 & 6.1 \\
\hline & Tennis & 6 & 1.9 \\
\hline & Volleyball & 10 & 3.2 \\
\hline & Total $(N)$ & 309 & 100 \\
\hline \multicolumn{4}{|l|}{ Sex } \\
\hline & Male & 178 & 57.6 \\
\hline & Female & 131 & 42.4 \\
\hline & Total $(N)$ & 309 & 100 \\
\hline \multicolumn{4}{|c|}{ Sport Visibility } \\
\hline & Highly Visible & 104 & 33.7 \\
\hline & Non-Highly Visible & 205 & 66.3 \\
\hline & Total $(N)$ & 309 & 100 \\
\hline \multicolumn{4}{|l|}{ Age } \\
\hline & 18 years & 35 & 11.3 \\
\hline & 19 years & 99 & 32.0 \\
\hline & 20 years & 63 & 20.4 \\
\hline & 21 years & 57 & 18.4 \\
\hline & 22 years & 37 & 12.0 \\
\hline & 23 years & 13 & 4.2 \\
\hline & 24 years & 4 & 1.3 \\
\hline & 25 years & 1 & .3 \\
\hline & Total $(N)$ & 309 & 100 \\
\hline \multirow[t]{2}{*}{ Race } & & & \\
\hline & White & 221 & 71.5 \\
\hline
\end{tabular}




$\begin{array}{cll}\begin{array}{lll}\text { Non-White } \\ \text { Total }(\boldsymbol{N})\end{array} & 88 & 28.5 \\ \text { Scholarship Status } & \mathbf{3 0 9} & \mathbf{1 0 0} \\ \text { Full } & 129 & \\ \text { Partial } & 133 & 41.7 \\ \text { None } & 47 & 43.0 \\ \text { Total }(\boldsymbol{N}) & \mathbf{3 0 9} & 15.2 \\ \text { Player Role } & & \mathbf{1 0 0} \\ \text { Starter } & 188 & 60.8 \\ \text { Non-Starter } & 121 & 39.2 \\ \quad \text { Total }(\boldsymbol{N}) & \mathbf{3 0 9} & \mathbf{1 0 0}\end{array}$

\section{Data Collection Procedures}

This study was administered at a small Division I University. Contact information for each team was obtained through the athletic department. The Athletics Committee was contacted to obtain permission for contact with student-athletes and the Human Subjects Review Board (IRB) was also contacted to obtain permission to conduct the study. The athletic department and athletic director were then contacted to obtain verbal permission to contact coaches of each team. Each prospective coach was contacted to obtain verbal consent and then sent a letter of information to explain the purpose of the study.

Upon receiving permission from the aforementioned constituents, meeting dates and times were arranged with the coaches and student-athletes in a place of convenience for each team. The researchers then administered the questionnaires to each team using a recruitment script. Informed consent was then given and obtained from all willing participants. After reading the informed consent document, participants were asked if they had any questions or needed clarification about the questionnaires involved. Upon satisfactorily answering questions or clarifying any issues, the participants were asked to complete and sign the informed consent document. Upon receiving informed consent, questionnaires were given to the athletes in individualized envelopes.

All questionnaires and informed consent documents were given to participants in individual envelopes labeled by number and grouped by sport. Following completion of each questionnaire packet (approximately five to ten minutes), participants were asked to place questionnaires and informed consent documents back into the envelopes and seal the envelopes to maintain anonymity and confidentiality. When data were entered for computer analysis, the number/code on the envelope was used to determine each participant in the computer file.

\section{Instruments}

Three questionnaires were given to participants to complete in-person at team meetings. In addition to the demographic questionnaire, participants completed the Perceived Motivational Climate in Sport Questionnaire-2 (PMCSQ-2) and the Student Athlete's Motivation toward Sports and Academics Questionnaire (SAMSAQ). To measure players' perceptions of the motivational climate on each team, the PMCSQ-2 (Newton, Duda, \& Yin, 2000) was used. The 33-item PMCSQ-2 was designed to assess players' perceptions of the motivational climate as either task- 
involving or ego-involving climates in a multi-dimensional hierarchical structure. The two respective climates are composites of six underlying characteristics. Task-involving climate items refer to three characteristics: (a) a sense that learning is encouraged; (b) each player has important roles on the team; and (c) effort and improvement is the emphasis of the climate. Ego-involving climate items refer to three characteristics: (a) a sense that mistakes are punished; (b) recognition by the coach is reserved for top athletes; and (c) rivalry to perform well among players on the team exists.

Adopting the task-involving or the ego-involving perspective in achievement activities is based on the theoretical perspective of dispositions in achievement goal theory (Nicholls, 1989) and the characteristics of such achievement (Ames, 1992). Assessments in goal orientation began in the academic setting measuring endorsement of task-orientation or ego-orientation and continued into the sport setting by developing the Task and Ego Orientation in Sport Questionnaire (TEOSQ; Duda, 1989; Duda \& Nicholls, 1992). Motivational climate goal structures, therefore, were then assessed in the educational setting in order to make theoretical distinctions between the task- and ego-involved climates (Ames \& Archer, 1988).

The independent variable of gender was assessed using the demographic questionnaire. The independent variable of perceived motivational climate for each individual was determined by a score on the PMCSQ-2. The dependent variable of motivation towards athletics and academics was determined by a score on the SAMSAQ. Scores on each questionnaire were run through SPSS's descriptive statistical analyses to measure for central tendency and variability for each independent variable.

The Student Athlete's Motivation toward Sports and Academics Questionnaire (SAMSAQ; Gaston-Gayles, 2004) was used to assess academic and athletic motivation. Since this questionnaire is copyrighted by the author, written consent was obtained by contacting Dr. GastonGayles and receiving an email giving permission to use the questionnaire. The SAMSAQ was developed to measure student-athletes' motivation towards sports and academics based on this expectancy-value framework (Gaston-Gayles, 2004; 2005).

The SAMSAQ is a 30-item instrument to which students responded on a 6-point Likerttype scale from 6 (very strongly agree) to 1 (very strongly disagree) and was developed to measure academic and athletic motivation of college athletes (Gaston, 2002). The initial scale consisted of 15 items to measure academic motivation and 15 items to measure athletic motivation. Exploratory factor analysis and reliability estimates were conducted to confirm the underlying structure of the initial scale, which led to a rotated three-factor solution. Common characteristics for each factor were found, which led to re-naming the factors appropriately. The SAMSAQ now consists of three different subscales: (a) student athletic motivation (SAM), which measures the extent to which individuals participated to pursue their sport (8 items); (b) academic motivation (AM) (16 items), which measures the extent to which an individual participated and was motivated toward academic-related tasks; and (c) career athletic motivation (CAM) (5 items), which measures a reflection of the desire to play sports at the professional or Olympic level (Gaston-Gayles, 2005).

Table 2 
Journal of Higher Education Athletics \& Innovation

Volume 1, Issue 5

Correlation Matrix of Variables for Academic Motivation

Variables

\begin{tabular}{|c|c|}
\hline AM & Task \\
\hline
\end{tabular}

\begin{tabular}{llllll} 
AM & 1.000 & & & \\
Task & $.292 * *$ & 1.000 & & \\
EgoAp & $-.100 *$ & $-.443 * *$ & 1.000 & & \\
EgoAv & $-.180 * *$ & $-.302 * *$ & $.459 * *$ & 1.000 & \\
Visib & $-.226 * *$ & -.049 & -.018 & .042 & 1.000 \\
Gender & $-.310 * *$ & -.054 & -.023 & $.111 *$ & $.445 * *$ \\
\hline
\end{tabular}

Note. $\mathrm{AM}=$ academic motivation (range from $1[$ low $]$ to $6[$ high $]$ ); Task = task-involving motivational climate (range from $1[$ low] to 5 [high]); EgoAp = ego approach-involving motivational climate (range from 1 [low] to 5 [high]); EgoAv = ego avoid-involving motivational climate (range from $1[$ low $]$ to $5[$ high]); Visib = sport visibility (highly visible sport or nonhighly visible sport); Gender = men's sport or women's sport.

$* p<.05 ; * * p<.01$ 
Journal of Higher Education Athletics \& Innovation

Volume 1, Issue 5

Table 3

Correlation Matrix of Variables for Sport Motivation

Variables

$\begin{array}{llllll}\text { SAM } & \text { Task } & \text { EgoAp } & \text { EgoAv } & \text { Visib } & \text { Gender }\end{array}$

SAM $\quad 1.000$

Task $\quad .334^{* *} \quad 1.000$

$\begin{array}{llll}\text { EgoAp } & -.166^{* *} \quad-.443^{* *} & 1.000\end{array}$

$\begin{array}{lllll}\mathrm{EgoAv} & -.109 * & -.302 * * & .459 * * & 1.000\end{array}$

$\begin{array}{llllll}\text { Visib } & .275^{* *} & -.049 & -.018 & .042 & 1.000\end{array}$

$\begin{array}{lllllll}\text { Gender } & .482^{* *} & -.054 & -.023 & .111^{*} & .445^{* *} & 1.000\end{array}$

Note. SAM = sport motivation (range from $1[$ low $]$ to $6[$ high $]$ ); Task = task-involving motivational climate (range from $1[l o w]$ to $5[$ high]); EgoAp = ego approach-involving motivational climate (range from $1[l o w]$ to $5[$ high]); EgoAv = ego avoid-involving motivational climate (range from $1[l o w]$ to $5[h i g h]$ ); Visib = sport visibility (highly visible sport or nonhighly visible sport); Gender = men's sport or women's sport.

$* p<.05 ; * * p<.01$ 


\section{Data Analysis and Findings}

Simultaneous multiple regression was conducted to determine the accuracy of the independent variables (i.e., gender, sport visibility, race, and perceived motivational climate) predicting academic and sport motivation. Data screening led to the elimination of one case, which exceeded the chi-square criteria based on the Mahalanobis Distance, $(N=309)$. Linearity was then analyzed by creating a scatterplot matrix and indicated normal distributions. Residual plots were also examined to determine multivariate normality and homoscedasticity and were found to be normally distributed. Therefore, multivariate normality and homoscedasticity were assumed.

Multiple regressions were conducted using the Enter method to determine whether the tvariables significantly predicted academic motivation. Tolerance statistics were examined and there were no violations. Regression results indicated an overall model of three predictors (gender, race, and task-involving climate) that significantly predicted academic motivation, $R^{2}=.205$, $R_{\text {adj }}^{2}=.189, F(6,302)=12.946, p<.001$. This model accounted for $21 \%$ of variance in academic motivation. When excluding the non-significant variables, the model including the significant variables of gender, race, and the task-involving climate accounted for $20 \%$ of variance in academic motivation. These results suggest that when the t-variable of gender increases by one, academic motivation changes by $25 \%$, holding the other independent variables constant. Gender contributed to the model of predicting academic motivation with a $t=-4.266$.

Regression results also indicated an overall model of two predictors (gender and taskinvolving climate) that significantly predicted sport motivation, $R^{2}=.396, R_{\text {adj }}^{2}=.384, F(6,302)=$ $33.018, p<.001$. This model accounted for $38 \%$ of variance in sport motivation. When excluding the non-significant variables, the model including the significant variables of gender, race, and the task-involving climate accounted for $39 \%$ of variance in academic motivation. These results suggest that when the independent variable of gender increases by one, sport motivation changes by $48 \%$, holding the other independent variables constant. Gender contributed to the model of predicting sport motivation with a $t=9.549$. The findings from this study suggest that the taskinvolving perceived motivational climate and gender (male vs. female sport) are significant predictors in the overall regression model measuring academic motivation and sport motivation.

More specifically, females had higher academic motivation $(M=4.85, S D=.40)$ than males $(M=4.47, S D=.67$; see Figure 1$)$. Females had lower sport motivation $(M=3.95, S D=$ $.53)$ than males $(M=4.59, S D=.61$; see Figure 2). Additionally, female student-athletes had higher academic motivation than sport motivation and male student-athletes had slightly higher sport motivation than academic motivation. Sport visibility (highly visible vs. non-highly visible sport), ego-involving approach perceived motivational climate, and ego-involving avoidance perceived motivational climate, however, were not found to be predictive of academic or sport motivation. 
Figure 1. Female vs. Male Academic Motivation.

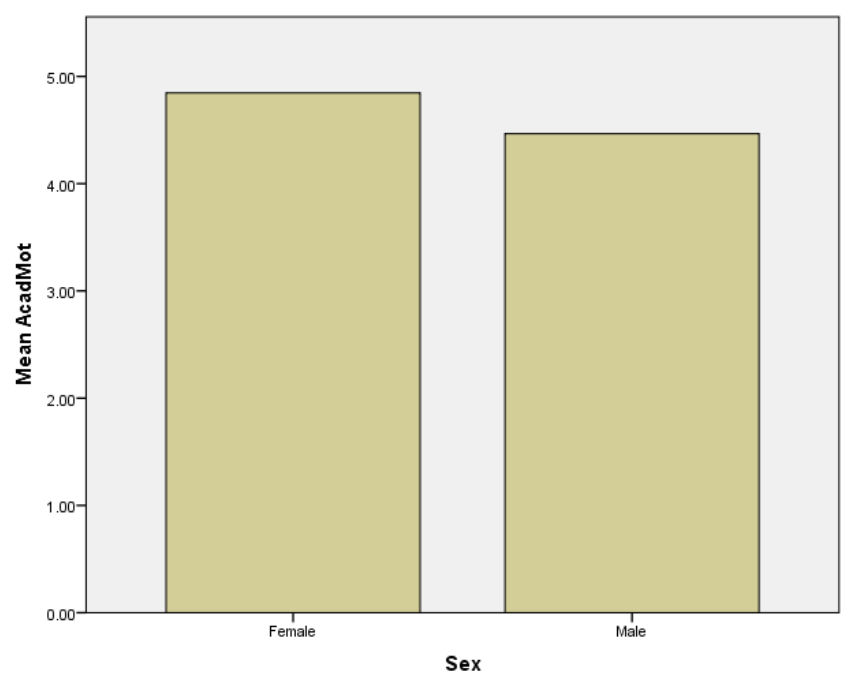

Figure 2. Female vs. Male Sport Motivation.

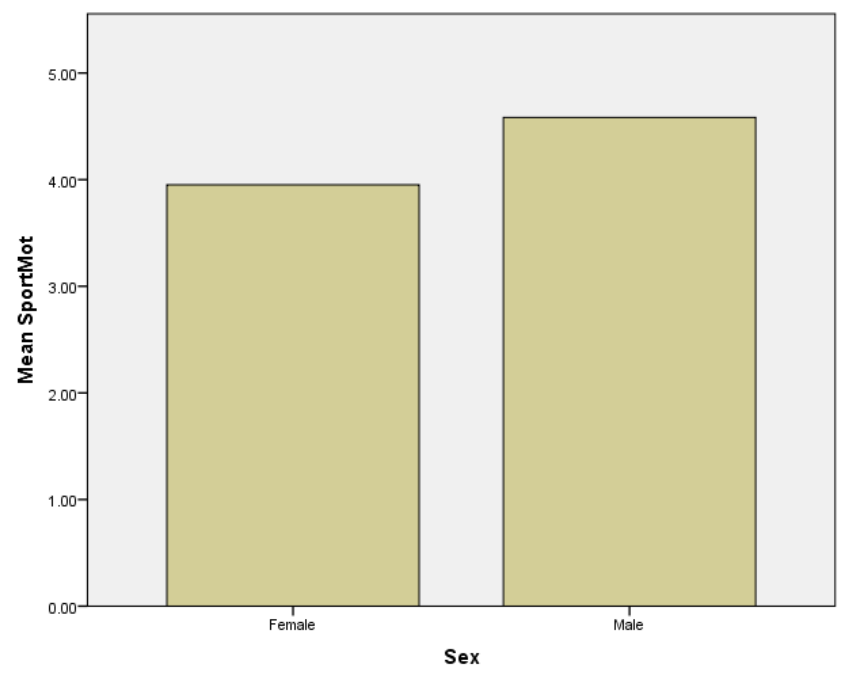


Due to the nature of the research question and the variables, methods of dummy coding were employed and assigned in data entry to give meaning to the categorical variables (Pedhazur, 1997). Thus, the results revealed whether gender was accounting for, or explaining, a statistically significant amount of variance in motivation among student-athletes. To test the relationship and degree of predictability among the variables, the assumptions of regression were checked in preanalysis data-screening procedures by first examining any outliers present, then examining the errors of prediction, or the residuals (Mertler \& Vannatta, 2010). This was done by examining the standardized residual plots created in SPSS to check for linearity (along with scatterplots), normality (along with the values for skewness, kurtosis, and Kolmogorov-Smirnov statistics), and homoscedasticity (along with Box's tests). Upon completion, linearity, multivariate normality, and homoscedasticity were assumed (Pedhazur, 1997). Furthermore, to address multicollinearity prior to the regression analysis, the correlation matrix was examined, along with an assessment of tolerance and the variance inflation factor (VIF) for the predictor variables (Stevens, 2001).

Upon completion of such examinations into the assumptions of multiple regression without violations, evidence of multicollinearity, and/or outliers, the researchers ran the multiple regression. The output was analyzed by interpreting the model summary, ANOVA table, and coefficients table to determine how well (level of significance) the independent variable predicted the dependent variables. Reliability values were examined for each instrument. The generalizability and transferability of the results were examined and discussed, as this study's variables of perceived motivational climate and motivation have been grounded in Newton et al.'s (2000) and Gaston-Gayles' (2004; 2005) works.

Principal components analysis was conducted on the items of the Student Athletes' Motivation toward Sports and Academics Questionnaire (SAMSAQ) utilizing a varimax rotation. The analysis produced a two-component solution, which was evaluated with the following criteria: eigenvalue, variance, scree plot, and residuals. Criteria indicated a two-component solution was appropriate, with the career motivation items loading into the sport motivation component.

After rotation, the first component accounted for $21.6 \%$ of the total variance in the original variables, while the second component accounted for $20.2 \%$ of the total variance in the original variables. The identified components were all common and had positive loadings above .437 . Component 1 consisted of 15 of the 30 items, with loadings ranging from .439-.767, all of which are labeled as "academic motivation items." Component 2 consisted of 13 items, with loadings ranging from .437-.750 and was labeled "sport motivation items." As previously mentioned, the original career motivation items from the questionnaire all loaded into the sport motivation component.

Standard multiple regression was then conducted to determine the accuracy of the independent variable predicting academic and sport motivation using the Enter method to determine whether the independent variable significantly predicted academic motivation. Tolerance statistics were examined and there were no violations. Regression results indicate an overall model of two predictors (gender and task-involving climate) that significantly predict academic motivation, $R^{2}=.187, R_{\text {adj }}^{2}=.174, \mathrm{~F}(5,303)=13.938, \mathrm{p}<.001$. This model accounted for $19 \%$ of variance in academic motivation. Regression results indicate an overall model of two predictors (gender and task-involving climate) that significantly predict sport motivation, $R^{2}=.372$, 
$R_{\text {adj }}^{2}=.362, F(5,303)=35.965, p<.001$. This model accounted for $37 \%$ of variance in sport motivation. In addition, bivariate and partial correlation coefficients between each predictor and the dependent variable are presented in Tables 4-7.

Table 4

Model Summary - Academic Motivation

\begin{tabular}{llllclll}
\hline Model & $R$ & $R^{2}$ & $R^{2}$ adj & $F$ & $p$ & $d f_{1}$ & $d f_{2}$ \\
\hline 1 & .432 & .187 & .174 & 13.938 & .000 & 5 & 303 \\
\hline
\end{tabular}

Table 5

Coefficients for Final Model - Academic Motivation

\begin{tabular}{llllll}
\hline & $B$ & $\beta$ & $t$ & Bivariate $r$ & Partial $r$ \\
\hline Visibility & -.128 & -.102 & -1.755 & -.226 & -.100 \\
Gender & -.288 & -.238 & -4.085 & -.310 & -.228 \\
Task & .342 & .271 & 4.639 & .292 & .257 \\
EgoAppr & .046 & .056 & .887 & -.100 & .051 \\
EgoAvoid & -.065 & -.093 & -1.574 & -.180 & -.090 \\
\hline
\end{tabular}

Table 6

Model Summary - Sport Motivation

\begin{tabular}{llllllll}
\hline Model & $R$ & $R^{2}$ & $R_{\text {adj }}^{2}$ & $F$ & $p$ & $d f_{1}$ & $d f_{2}$ \\
\hline 1 & .610 & .372 & .362 & 35.965 & .000 & 5 & 303 \\
\hline
\end{tabular}

Table 7 
Coefficients for Final Model - Sport Motivation

\begin{tabular}{llllll}
\hline & $B$ & $\beta$ & $t$ & Bivariate $r$ & Partial $r$ \\
\hline Visibility & .120 & .086 & 1.699 & .275 & .097 \\
Gender & .624 & .472 & 9.202 & .482 & .467 \\
Task & .624 & .359 & 7.004 & .334 & .373 \\
EgoAppr & .037 & .040 & .726 & -.166 & .042 \\
EgoAvoid & -.057 & -.075 & -1.436 & -.109 & -.082 \\
\hline
\end{tabular}

\section{Discussion}

Motivation is frequently associated with success, and success contributes to personal growth (Deci \& Ryan, 1985; Ryan \& Deci, 2000b). An athlete is motivated towards personal growth in his/her chosen sport, which in turn is associated with personal success. This study sought to determine whether being a member of a men's versus women's sport can significantly predict motivation towards academics and/or athletics. The researchers conclude that gender is a significant predictor of motivation towards both academics and athletics. More specifically, females had higher academic motivation $(M=4.85, S D=.40)$ than males $(M=4.47, S D=.67)$. Females had lower sport motivation $(M=3.95, S D=.53)$ than males $(M=4.59, S D=.61)$. Additionally, female athletes had higher academic motivation than sport motivation and male student-athletes had slightly higher sport motivation than academic motivation.

In support of the current findings of gender being a significant predictor of motivation, Medic et al. (2007) found that male athletes $(M=4.83, S D=1.01)$ reported higher extrinsic motivation than females. It follows that this study supports such a concept that male athletes reported higher motivation towards athletics than female athletes. Similarly, Adler and Adler's (1987) and Meyer's (1990) results indicated several similarities and differences among male and female student-athletes. That is, academic disengagement did not emerge among the female student-athletes as it did among their male counterparts. Instead, conditions in their athletic, academic, and social lives actually encouraged academic achievement among the female studentathletes; they exhibited an increased commitment to academic completion over the course of their degree (Meyer, 1990). As such, this study also found that female athletes were more academically motivated than their male counterparts, even taking into consideration the changes that have happened in intercollegiate athletics since these studies, specifically in academic requirements and commercialism. Such results in both Meyer's (1990) study and the current study revealed interesting insights into the differences between men's and women's teams in intercollegiate athletics. 
Different perspectives of college athletes might also explain differences between male and female athletes. For example, Abrahamsen, Roberts, and Pensgaard (2008) found that females were more impacted by the motivational climate in that it caused them to lose concentration more than their male counterparts. This may show that the motivational climate does in fact play a larger role in female athletes as opposed to male athletes, which might also explain differences in motivation among athletes. Additionally, male and female student-athletes might have different beliefs about their ability in either athletics or academics, which could affect differing levels of motivation. For example, the mastery (task) climate was associated with a high level of perceived ability for both male and female athletes, although females tended to show lower perceptions of ability than their male counterparts (Abrahamsen et al., 2008). Therefore, it is important to assess perceived motivational climate, and its relationship to other factors such as motivation and team membership among student-athletes in collegiate settings. Further research in these areas is suggested.

Examining main effects of race/ethnicity, gender, and sport on motivation in GastonGayles' $(2004 ; 2005)$ study, results indicated that females had significantly higher academic motivation than males $(F=8.08, p<.01)$, males had significantly higher athletic motivation scores than females $(F=16.64, p=.000)$. This was also true in the current study. These findings support further examination into such factors, as the author suggests that, "perhaps the most meaningful application of the scale might be as an assessment of athletes' motivation" (Gaston-Gayles, 2005, p. 324).

Unlike the findings that sport visibility does not significantly predict motivation, Simons, Van Rheenen, and Covington (1999) conducted a study that support gender as a significant predictor of academic and sport motivation. They used a motivational typology based on selfworth theory and achievement motivation, which was proposed in the earlier work of Covington's (1992) four motivational types: (a) success-oriented; (b) failure-avoiders; (c) over strivers; and (d) failure-acceptors. Simons et al. (1999) found that those students who were classified as failureacceptors were more committed to their sport than success-oriented student-athletes. Additionally, the failure-acceptor athletes were male and played revenue (highly visible) sports such as football and basketball than the other student-athletes. Since the failure-acceptors had little or no interest in academics, motivation towards athletics seemed to be the main factor in attending college. The researchers therefore suggested that the nature of intercollegiate athletics to pressure college athletes to focus on athletics might lead to a lesser commitment to academics. As such, athletic departments should provide additional support for athletes such as academic support and career support that includes life skills.

Similar to the current findings, Carter's (2012) examination of student-athlete motivations toward both academics and athletics at a Division I university demonstrated that motivational orientations of athletes differed when accounting for gender. Shuman (2009) also found that female student-athletes were more likely to be academically motivated than male athletes, which was also similar to Simons et al.'s (1999) and Ridpath's (2002; 2007) findings that female studentathletes were better able to balance athletics and academics than male student-athletes.

In support of the current findings of gender being a significant predictor of motivation, Medic et al. (2007) found that male athletes with scholarships $(M=4.83, S D=1.01)$ reported 
higher extrinsic motivation than females with scholarships. It follows that this study supports such a concept that male athletes reported higher motivation towards athletics than female athletes. Similarly, Adler and Adler's (1987) and Meyer's (1990) results indicated several similarities and differences among male and female student-athletes. That is, academic disengagement did not emerge among the female student-athletes as it did among their male counterparts. Instead, conditions in their athletic, academic, and social lives actually encouraged academic achievement among the female student-athletes; they exhibited an increased commitment to academic completion over the course of their degree (Meyer, 1990). As such, this study also found that female student-athletes were more academically motivated than their male counterparts. Such results in both Meyer's (1990) study and the current study revealed interesting insights into the differences between men's and women's teams in intercollegiate athletics.

Another similar study to add substance to the current findings that gender is a significant predictor of academic and sport motivation and unlike the findings that sport visibility does not significantly predict motivation was the one previously mentioned in the discussion by Simons et al. (1999). The researchers agree that the nature of intercollegiate athletics to pressure studentathletes to focus on athletics might lead to a lesser commitment to academics.

As student-athletes have different perspectives than the normal population of college students, this can also explain differences between male and female athletes. For example, Abrahamsen et al. (2008) found that male and female elite athletes tended to have similar and different views of the motivational climate. In other words, elite athletes are aware of the differences between a task-involved motivational climate and an ego-involved motivational climate (although they may not know the specific names of each). Females were more impacted by the motivational climate than their male counterparts in that it caused them to lose concentration more. This may show that the motivational climate does in fact play a larger role in female athletes as opposed to male athletes, which might also explain differences in motivation among athletes.

Additionally, male and female student-athletes might have different beliefs about their ability in either athletics or academics, which could affect differing levels of motivation. For example, the mastery (task) climate was associated with a high level of perceived ability for both male and female athletes, although females tended to show lower perceptions of ability than their male counterparts (Abrahamsen et al., 2008). Therefore, the researchers would like to highlight the importance of assessing perceived motivational climate, and its relationship to other factors, such as motivation and team membership among student-athletes in collegiate settings.

Gaston-Gayles' (2004; 2005) research was instrumental in academic and athletic motivation in intercollegiate athletics. Research utilizing her constructs is limited, however. Similar to the current findings, Carter's (2012) examination of the motivations toward both academics and athletics of student-athletes at a Division I university demonstrated that motivational orientations of student-athletes differed when accounting for gender. Moreover, Shuman's (2009) dissertation assessed 275 Division I student-athletes' motivation towards athletics, academics, and careers by utilizing Gaston-Gayles' (2004) SAMSAQ. Similar to the current study's results, Shuman (2009) found that female student-athletes were more likely to be academically motivated than male student-athletes, which was also similar to Simons et al.'s (1999) findings that female student-athletes were better able to balance athletics and academics 
than male student-athletes. This study also found that gender significantly predicted academic and athletic motivation. Specifically, female student-athletes were more academically motivated than male student-athletes and male student-athletes were more athletically motivated than female student-athletes (see Table 8).

Table 8

Summary of Findings

\begin{tabular}{lc}
\hline Research Question & Findings \\
\hline $\begin{array}{l}\text { Does gender significantly predict } \\
\text { academic/athletic/career motivation among }\end{array}$ & $\bullet$ Gender significantly predicted \\
student-athletes, controlling for other & academic and athletic/career \\
variables in the model? & motivation among student-athletes \\
& $\bullet \begin{array}{l}\text { Males had higher athletic motivation } \\
\text { than females }\end{array}$ \\
& $\bullet \begin{array}{l}\text { Females had higher academic } \\
\text { motivation than males }\end{array}$ \\
\hline
\end{tabular}

\section{Limitations of Study}

The variables in this study were chosen on the basis of available instruments and time constraints. A limitation to this study is the time period and the stratification of the sample. The researchers collected data during the 2014 spring semester, which is another parameter that is based on time constraints. Ideally, college athletes' motivation towards athletics and academics would be studied both in-season and during the off-season for all participants. This study had participants who were in-season and participants who were in the off-season.

The majority of limitations come with the sample that the study used. That is, due to the sample coming from one Division I university, it was not possible to generalize the results beyond this university and its sample of student-athletes. Teams and athletes in different areas and conferences with players of varying skill levels may differ for each variable being tested. In particular, the way a player perceived his/her leader's motivation might differ at larger or smaller universities.

Furthermore, a non-random sampling method of convenience was utilized due to the accessibility of the institutional population to one of the researchers. Additionally, the researchers had experience and rapport with the athletic department in which the participants resided. Upon collecting all pertinent data, there are specific assumptions about the study. One assumption is that participants are willing to participate and answer all questions on the questionnaires honestly, truthfully, and accurately. Participants were assumed to sincerely and openly answer each question of each questionnaire. Once participants read and signed informed consent forms, it was assumed that participants were voluntarily participating in the study. That is, participants did not feel any pressure or coercion to participate in the study. Participants were assumed to be genuine and thoughtful in answering such questions. In addition, participants were assumed to understand each question fully and precisely in order to accurately answer such questions. Finally, it was assumed 
that data collection would be consistent across all teams and participants. Utilizing the recruitment script assisted in such consistency. Thus, upon collecting all data per team, the researchers assumed that all participants had an equal understanding of the study and the procedures for filling out the related questionnaires.

\section{Implications for Practice and Future Research}

Reasons for motivation toward academics and/or athletics may vary among participants in men's and women's sports. As levels of motivation for such participants were suggested to be explored further to draw more firm conclusions and generalizations by conducting similar studies with different samples (Ryan \& Deci, 2000a), in the current study, gender was found to significantly predict motivation towards both academics and athletics. Adding substance to the current findings, Gaston-Gayles (2004; 2005) examined an overall model that included race/ethnicity, gender, and sport visibility. Her significant results also indicated that females had significantly higher academic motivation than males and males had significantly higher athletic motivation scores than females. This was also true in the current study. Additionally, Shuman (2009) found that female student-athletes were more likely to be academically motivated than male student-athletes, which was also similar to Simons et al.'s (1999) findings that female studentathletes were better able to balance athletics and academics than male student-athletes.

Popular culture in the aforementioned situations increases student-athletes' motivation toward either academics or athletics (Comeaux \& Harrison, 2001). Images in the media of successful male student-athletes who play professionally are a part of such use of popular culture. Additionally, the use of popular culture as it relates to college academics has been shown to give female student-athletes ownership of their learning and academic pursuit (Comeaux \& Harrison, 2001). Such ownership can lead to higher levels of motivation towards academics for female student-athletes.

This study has several potential implications for leaders in intercollegiate athletics including those among universities, athletic departments, academic support personnel, and coaches. Additionally, there are several implications for future research utilizing such variables and constructs. The results from this study, along with the research involved, provide insight and information about practical considerations concerning academic motivation in college studentathletes. For example, it is helpful to confirm that college athletes participating in men's and women's sports differ in the significant prediction of academic motivation. As such, male and female college athletes should be monitored as individuals in levels of motivation towards academics and athletics through academic support, coaches, and administrators in the athletic departments. It is also helpful to note that those athletes who perceive a task-involved motivational climate serve as a significant predictor of academic and sport motivation. Several Division I institutions already have an academic support program in place for college athletes (Holsendolph, 2006). These findings provide evidence that administrators should not only continue this practice, but also increase their awareness in individual differences among the athletes. For example, administrators might approach members of men's and women's sports differently in the area of academic support with intentional attention to individuality. 
These results also support requests for increased hiring and staffing in student-athlete service departments to adequately suit the needs and requirements of student-athletes' motivation. These results contribute to the body of research that supports further investigation into the academic and sport motivation in college student-athletes (Gaston-Gayles, 2004; Simons \& Van Rheenen, 2000; Simons et al., 1999; Snyder, 1996). The findings also contribute to the generalizability and further exploration of the factor structures of both the PMCSQ-2 and the SAMSAQ. Refining each instrument to better reflect the constructs of the variables would be beneficial. Additionally, published work utilizing the SAMSAQ is virtually non-existent since Gaston-Gayles' (2004, 2005) investigation at a large, Division I institution. Utilizing this measurement of motivation in different populations that have different student-athletes in different contexts would contribute to the reliability and validity of the instrument and the overall understanding of its constructs. 


\section{References}

Abrahamsen, F. E., Roberts, G. C., \& Pensgaard, A. M. (2008). Achievement goals and gender effects on multidimensional anxiety in national elite sport. Psychology of Sport and Exercise, 9, 449-464.

Adie, J. W., Duda, J. L., \& Ntoumanis, N. (2008). Achievement goals, competition appraisals, and the psychological and emotional welfare of sport participants. Journal of Sport \& Exercise Psychology, 30, 302-322.

Adler, P., \& Adler, P. (1987). Role conflict and identity salience: College athletics and the academic role. The Social Science Journal, 24, 443-455.

Allen, J. B., \& Howe, B. L. (1998). Player ability, coach feedback, and female adolescent athletes' perceived competence and satisfaction. Journal of Sport \& Exercise Psychology, 20, 280-299.

Ames, C. (1992). Achievement goals, motivational climate, and motivational processes. In G.C. Roberts (Ed.), Motivation in sport and exercise (pp. 161-176).

Ames, C., \& Archer, J. (1988). Achievement goals in the classroom: Students' learning strategies and motivation. Journal of Educational Psychology, 80, 260-267.

Amorose, A. J., \& Horn, T. S. (2001). Pre- to post-season changes in the intrinsic motivation of first year college athletes: Relationships with coaching behavior and scholarship status. Journal of Applied Sport Psychology, 13, 355-373.

Amorose, A. J. (2003). Reflected Appraisals and Perceived Importance of Significant Others' Appraisals as Predictors of College Athletes' Self-Perception of Competence. Research Quarterly for Exercise and Sport, 74:1, 60-70. 
Balaguer, I., Duda, J. L., \& Crespo, M. (1999). Motivational climate and goal orientations as predictors of perceptions of improvement, satisfaction and coach ratings among tennis players. Scandinavian Journal of Medicine and Science in Sports, 9, 381388.

Benford, R. D. (2007). The college sports reform movement: Reframing the "Edutainment" industry. The Sociological Quarterly, 48, 1-28.

Carter, C. M. (2012). Academic and athletic motivation as predictors of academic performance of Division I college student-athletes. (Unpublished doctoral dissertation). University of Oklahoma, Norman, Oklahoma.

Comeaux, E. \& Harrison, C.K. (2001) A conceptual model of academic success for studentathletes. Educational Researcher, 40, 235-245.

Covington, M. V. (1992). Making the grade: A self-worth perspective on motivation and school reform. New York, NY: Cambridge University Press.

Deci, E. L., \& Ryan, R. M. (1985). Intrinsic motivation and self-determination in human behavior. New York, NY: Plenum Press.

Duda, J. L. (1989). The relationship between task and ego orientation and the perceived purpose of sport among male and female high school athletes. Journal of Sport \& Exercise Psychology, 11, 318-335.

Duda, J. L., \& Nicholls, J. G. (1992). Dimensions of achievement motivation in schoolwork and sport. Journal of Educational Psychology, 84, 290-299.

Eccles, J. (1983). Expectancies, values, and academic behaviors. In J. T. Spence (Ed.), Achievement and sociological approaches (pp. 76-138). San Francisco, CA: W.H. Freeman.

Gaston, J. L. (2002). A study of student athletes' motivation towards sports and academics. Unpublished doctoral dissertation, The Ohio State University, Columbus, $\mathrm{OH}$. 
Gaston-Gayles, J. L. (2004). Examining academic and athletic motivation among student athletes at a Division I university. Journal of College Student Development, 45, 75-83.

Gaston-Gayles, J. L. (2005). The factor structure and reliability of the student athletes' motivation toward sports and academic questionnaire (SAMSAQ). Journal of College Student Development, 46(3), 317-327.

Harter, S. (1978). Effectance motivation reconsidered: Toward a developmental model. Human Development, 21, 34-64.

Hollembeak, J., \& Amorose, A. J. (2005). Perceived coaching behaviors and college athletes' intrinsic motivation: A test of self-determination theory. Journal of Applied Sport Psychology, 17, 20-36.

Holsendolph, E. (2006). When Academics and Athletics Collide. Retrieved from https://diverseeducation.com/article/5704/

Medic, N., Mack, D. E., Wilson, P. M., \& Starkes, J. L. (2007). The effects of athletic scholarships on motivation in sport. Journal of Sport Behavior, 30, 292.

Mertler, C. A., \& Vannatta, R. A. (2010). Advanced and multivariate statistical methods: Practical application and interpretation ( $4^{\text {th }}$ ed.). Los Angeles, CA: Pyrczak.

Meyer, B. (1990). The academic performance of female collegiate athletes. Sociology of Sport Journal, 7, 44-57.

Meyer, S. K. (2005). NCAA academic reforms: Maintaining the balance between academics and athletics. Phi Kappa Phi Forum, 85(3), 15-19.

NCAA. (2002, September 30). Division I athlete graduation rate reaches 60\%. NCAA News. Retrieved from http://www.ncaa.org

NCAA. (2012). NCAA Division I graduation rates summary. NCAA. Retrieved from http://www.ncaa.org 
Newton, M. L., Duda, J. L., \& Yin, Z. (2000). Examination of the psychometric properties of the Perceived Motivational Climate in Sport Questionnaire-2 in a sample of female athletes. Journal of Sport Sciences, 18, 275-290.

Nicholls, J. G. (1984). Achievement motivation: Conceptions of ability, subjective experience, task choice, and performance. Psychological Review, 91, 328-346.

Nicholls, J. G. (1989). The competitive ethos and democratic education. Cambridge, MA: Harvard University Press.

Pappano, L. (2012). How big time college sports ate college life. Retrieved from http://www.nytimes.com/2012/01/22/education/edlife/how-big-time-sportsate-collegelife.html?pagewanted=all

Pascarella, E. T., \& Terenzini, P. T. (2005). How college affects students: A third decade of research. San Francisco, CA: Jossey-Bass.

Pedhazur, E. J. (1997). Multiple regression in behavioral research: Explanation and prediction. ( $3^{\text {rd }}$ ed.). Orlando, FL: Harcourt Brace College Publishers.

Rader, B. G. (2009). American sports: From the age of folk games to the age of televised sports ( $6^{\text {th }}$ ed.). Upper Saddle River, NJ: Pearson Prentice Hall.

Reinboth, M., \& Duda, J. L. (2004). The motivational climate, perceived ability, and athletes' psychological and physical well-being. The Sport Psychologist, 18, 237-251.

Ridpath, B. (2002). NCAA student athlete characteristics as indicators of academic achievement and graduation from college. Ann Arbor, MI: UMI Dissertation Services, Pro Quest.

Ridpath, B., Kiger, J., Mak, J. Y., Eagle, T., \& Letter, G. (2007). Factors that influence the academic performance of NCAA Division I athletes. Sport Management and Related Topics Journal (SMART), IV, 1.

Ryan, R. M., \& Deci, E. L. (2000a). Intrinsic and extrinsic motivations: Classic definitions and new directions. Contemporary Educational Psychology, 25, 54-67. 
Ryan, R. M., \& Deci, E. L. (2000b). Self-determination theory and the facilitation of intrinsic motivation, social development, and well-being. American Psychologist, 55, 6878.

Sheldon, J. P., \& Eccles, J. S. (2005). Physical and psychological predictors of perceived ability in adult male and female tennis players. Journal of Applied Sport Psychology, 17, 48-63.

Shuman, M. P. (2009). Academic, athletic, and career athletic motivation as predictors of academic performance in student athletes at a Division I University. (Unpublished doctoral dissertation). The University of North Carolina at Greensboro.Silva III, J. M., \& Weinberg, R. S. (Eds). (1984). Psychological foundations of sport. Champaign, IL: Human Kinetics.

Silva, J., \& Weinberg, R.(Eds.).(1984).Psychological Foundations of Sport. Champaign, IL: Human Kinetic Publishers

Simons, H. D., \& Van Rheenen, D. (2000). Noncognitive predictors of student athletes' academic performance. Journal of College Reading and Learning, 30, 167-181.

Simons, H. D., Van Rheenen, D., \& Covington, M. V. (1999). Academic motivation and the student athlete. Journal of College Student Development, 40, 151-162.

Snyder, P. L. (1996). Comparative levels of expressed academic motivation among Anglo and African American university student-athletes. Journal of Black Studies, 26, 651-667.

Splitt, F. (2002). Reclaiming academic primacy in higher education. Chicago, IL: Northwestern University Press.

Stevens, J. (2001). Applied multivariate statistics for the social sciences. ( ${ }^{\text {th }}$ ed.). Hillsdale, NJ: Lawrence Erlbaum Associates.

The Harris Poll. (2013). NFL most popular for $30^{\text {th }}$ year in a row [Data file]. Retrieved from https://www.google.com/\#q=the+harris+poll+sports+popularity+2014 
Tsang, E. C. K. (2007). Path analysis on the influence of perceived sport competence by other motivational variables. Journal of Physical Education \& Recreation, 13.

Van-Yperen, N. W., \& Duda, J. L. (1999). Goal orientations, beliefs about success, and performance improvement among young elite Dutch soccer players. Scandinavian Journal of Medicine and Science in Sports, 9, 358-364.

Vroom, V. (1964). Work and motivation. New York, NY: Wiley.

Weiner, B. (1984). Human motivation: Metaphors, theories, and research. Newbury Park, CA: Sage. 